\section{United Nations Gopher.}

Access: gopher://gopher. undp.org. Contact: UNDP gopher administrator, root@ undp.org.

Electronic access to United Nations documents has two obvious advantages over print: timeliness and ease of distribution. The United Nations gopher represents a commitment to both and, although still relatively small, promises improved access to information generated by and about this important international body

The opening menu features 14 choices. Although there is no menu item offering a keyword search of the directories, files, or contents of the U.N. gopher, the available categories are clearly labeled and organized. The first"The United Nations, what it is and what it does"-provides the full text of the U.N. Charter, the Statute of the International Court of Justice, and the Universal Declaration of Human Rights, as well as folders of additional material describing the U.N. system, organization, resources, and peacekeeping functions.

The second item on the opening menu links the user to the daily journal and to press briefings and releases, current-year Security Council resolutions, and statements by the Secretary General. Users with only a vague idea of when the Security Council passed a particular resolution may find the chronological ordering cumbersome as they work first through filenames such as "94-03: March 94/" and then through files labeled with resolution numbers rather than with topical keywords. The rapid availability of the resolutions probably outweighs such inconveniences for many researchers, however.

Menu categories for General Assembly and Security Council material and documents from such widely publicized meetings as the International Conference on Population and Development contribute to the gopher's usefulness. The United Nations Economic and Social Council has its own spot on the menu; it includes a link to the Commission on Sustainable Devel-

Sara Amato is automated systems librarian at Central Washington University; samato@taboma.cwu.edu opment gopher complete with an excellent users' manual. Another main menu heading, "United Nations Development Programme (UNDP) Documents," provides the UNDP's statement of purpose, a description of the organization, a well-organized collection of statements by officials, and similar documents. The U.N. gopher also makes it easy to connect to the gophers of the International Atomic Energy Agency, International Telecommunication Union, North Atlantic Treaty Organization, United Nations Children's Fund, the World Health Organization, the World Bank, etc.

Two items on the U.N. Gopher main menu lead to directories and a telecommunications catalog for phone numbers and e-mail addresses of individuals affiliated with the U.N. Selections for environmental information, other gopher servers, and external public databases provide connections to networked resources beyond those offered by the U.N., while two final menu items celebrate the organization's 50th anniversary and announce new developments.

As the UN gopher continues to grow, it will serve as a timely and easily accessible alternative to the rather slow pulblishing program of the organization and its many affiliated agencies. College students, Model U.N. participants, researchers, and the librarians who serve them will find much to appreciate about the U.N. Gopher.-Cheryl Knott Malone, University of Texas at Austin; ckmalone@mail.utexas.edu

\section{Chorus: A Resource for Academic and Educational Computing in the Arts/Hu-} manities. Access: hitp://www peinet.pe,ca: 2080/Chorus/home.html.

Chorus, according to its own introduction, "is a resource for academic and educational computing in the arts/humanities. (The terms 'arts' and 'humanities' are used to refer to the study of language, both modern and classical; linguistics; literature; history; philosophy; archaeology; religion; ethics; the history, criticism, and theory of the arts; those areas of education and social science which have humanistic content and/or employ humanistic methods; and, 
theology." The project is coordinated by Todd J. B. Blayone, faculty lecturer at McGill University. His previous experience in presenting material of this type comes from a stint as guest editor for Offline: Computer Research for Religious Studies.

Chorus is not envisioned as a serial publication, but as a site, in the true sense of a place, which will evolve and grow over time and as more and more people contribute. The resource offers feature articles,

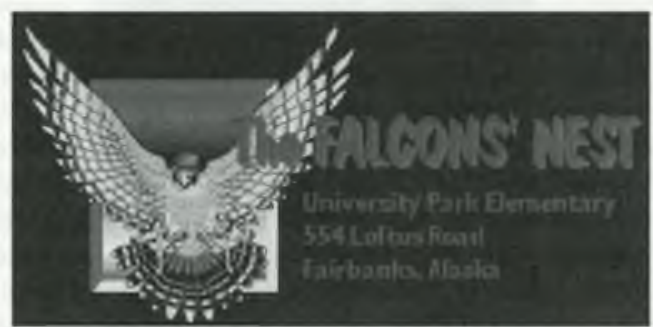

This graphic is from the Fairbanks, Alaska, University Park Elementary School's home page, a link from City.Net. software reviews, book reviews, and links to other resources in the fields of humanities and humanities computing, and is actively soliciting qualified contributors and section editors at present. The editorial team, as it stands, comprises an impressive array of personnel, including faculty from Yale, the University of Connecticut, McGill, the University of Durham, Notre Dame, and other schools.

The initial feature articles include "Electronic Shakespeare: Making Texts Compute" by Eric Johnson, and "Towards a Virtual University" by L. Gregory Bloomquist.

This is a promising site, especially exciting in its incipient ability not only to describe, but to demonstrate principles of computing applications vis-à-vis the humanities. The design of Chorus is professional and attractive as well as easily navigated. Care is given to the citation of sources, and to the creclentials of the contributors.-David Dodd, University of Colorado at Colorado Springs; ddodd@serf.uccs.edu

City.Net. Access: http://www.city.net/.

Those who recall a frantic rustling of Newsweek pages in the days following last year's South African elections, when students rushed in to locate the new flag of the nation, might enjoy examining the many sites accessible through City.Net. A wide variety of questions may be answered using this web server operated by City Net Express of Portland, Oregon. Begun in 1994 by former Intel systems engineer Kevin Altis, this rapidly growing site arranges and provides links to city, regional, and country home pages around the world.

The simple name belies the real strength of this resource in that it functions as an electronic hybrid of many kinds of reference materialspart atlas, part gazetteer, part almanac, and much more. This resource will appeal to a multidisciplinary audience, and could be an appropriate stop for undergraduates seeking data on travel and tourism, marketing, demographics, government and politics, and social and cultural topics. City. Net also may prove to be of equal value to librarians seeking answers to ready-reference or "stumper" questions.

The resource is well organized and extremely easy to browse, and the screen displays for the home pages of sites are simply designed. There are links at the bottom of each home page back to the index from which one began a search, along with four alphabetical indexes to cities, states or provinces, regions, and countries. While there is no online help, one should remember that this is essentially a directory; such help is likely unnecessary. The site administrators have placed clearly marked links on the home page that users may select to post questions to City.Net. And this reviewer consistently has received a response to all of his queries within a matter of hours. The chief flaw in this resource appears to be a bug in the keyword search engine, which presently returns zero hits with some frequency. City. Net staff are currently working to correct this problem.

The typical city page offers one or more city guides from which to choose, along with maps, transit schedules, and other general information. The guides, and the city pages themselves, typically include a mix of travel, business, and entertainment materials most of interest to business, marketing, or travel students. And while there is substantial data in some city pages, the real value of this resource lies in the vast amount of information included in the many links to foreign countries. By browsing the country pages one may locate an astounding variety of eclectic facts, from summary tables of the 1991 India census, to 1811-1991 population tables for Scotland. Need to know the state flower of Malaysia? Try City.Net. And don't forget - those country flag illustrations are just a mouse click away._-John Creech. Willamette University Library 